\title{
Blood Stream Infection in Pediatric Patients of a Tertiary Care Hospital: A Bacteriological and Antimicrobial Profile
}

\author{
A. Ramya*, S. Sangeetha, S.A. Lakshminarayana and R. Prakash \\ Department of Microbiology, Rajarajeswari Medical College and Hospital, Bengaluru, India \\ *Corresponding author
}

\begin{tabular}{|c|}
\hline Keywords \\
\hline $\begin{array}{l}\text { Blood stream } \\
\text { infection, } \\
\text { Staphylococcus, } \\
\text { Klebsiella, } \\
\text { Antimicrobial } \\
\text { profile. }\end{array}$ \\
\hline Article Info \\
\hline $\begin{array}{l}\text { Accepted: } \\
22 \text { February } 2017 \\
\text { Available Online: } \\
10 \text { March } 2017\end{array}$ \\
\hline
\end{tabular}

Blood stream infections are very common in the pediatric age group and these are one of the common causes of morbidity and mortality in neonates and children. In developing countries, the rate of blood stream infections in children is about 20$50 \%$ and it is estimated that one in five neonates is suffering from and blood infection. The present study was undertaken to determine the etiological agents causing blood stream infection and their antibiotic susceptibility patterns in pediatric patients. A total of 3255 samples with suspected septicaemia were processed aerobically. Culture positivity was 4.4\%. Coagulase negative Staphylococci $(53.65 \%)$ was the commonest isolate followed by K. Pneumoniae (35.48\%). Around $27.27 \%$ of MRSA and $12.9 \%$ of ESBL producers were isolated in our study. All GPCs were $100 \%$ sensitive to vancomycin and teicoplanin and GNBs were $100 \%$ sensitive to colistin. Repeated isolation of doubtful pathogens confirms true bacteraemia. Specific antibiotic utilisation strategies like antibiotic restriction, combination therapy and antibiotic escalation and de-escalation may help to decrease or prevent the emergence of resistance.

\section{Introduction}

Blood stream infections are very common in the pediatric age group and these are one of the common causes of morbidity and mortality in neonates and children (Meremkwer et al., 2005). In developing countries, the rate of blood stream infections in children is about $20-50 \%$ and it is estimated that one in five neonates is suffering from blood infection (Anuradha et al., 1995; Elster et al., 2005).

Blood stream infection is caused by a variety of Gram-positive as well as Gram-negative bacteria, and sometimes yeasts (Gomaa et al., 2001). The spectrum of causative organisms changes over times and varies from region to region. This is due to the changing pattern of antibiotic use and changes in lifestyle (Shrestha et al., 2008).

Several risk factors have been identified both in the neonates and children, which make them susceptible to infections. The risk factors for neonatal septicemia include premature rupture of membrane, prolonged rupture, prematurity, urinary tract Infection, 
poor maternal nutrition, low birth weight, birth asphyxia and congenital anomalies (Meremkwer et al., 2005). While in children are serious injury, chronic antibacterial therapy, malnourishment, chronic medical problems, and immuno-suppressants therapy constitute the risk factors for septicemia. Polymicrobial sepsis occurs in high risk patients and is associated with catheters, gastrointestinal diseases, neutropenia and malignancy (Enrione et al., 2007).

Children with septicemia present with fever, difficulty in breathing, tachycardia, malaise, refusal of feeds or lethargy (Nwadioha et al., 2010). They can have serious consequences like shock, multiple organ failure, disseminated intravascular coagulation, etc. Thus, the blood stream infections constitute one of the most serious situations and, as a result, timely detection and identification of blood stream pathogen is important (Mackie and MacCartney). Clinical assessment using a combination of symptoms and signs is a useful guide for the provisional diagnosis of septicemia. But bacteriologic culture to isolate the offending pathogen remains the mainstay of definitive diagnosis of septicemia (Meremkwer et al., 2005).

The choice of empirical antimicrobial requires the knowledge of the epidemiology of common pathogens in the given setting, which constantly changes, necessitating periodic review and their sensitivity profile. Furthermore, this knowledge would help us formulate an antibiotic policy. The present study was designed and implemented to determine the etiology of blood stream infections in pediatric patients and to examine antibiotic susceptibility patterns of the isolated organisms.

\section{Materials and Methods}

The study was conducted in the department of Microbiology, Raja Rajeswari Medical
College and Hospital, Bengaluru from January 2014 to September 2015.

Under aseptic precautions, paired blood samples were collected from a total of 3255 patients with suspected blood stream infections. One milliliter (neonates) and $5 \mathrm{ml}$ (children) blood was collected and inoculated into 10 and $50 \mathrm{ml}$ of brain heart infusion broth (1:10 dilution) respectively. The culture bottles were incubated at $37^{\circ} \mathrm{C}$ aerobically and periodic subcultures were done day 2 , day 4 and finally on day 7 onto blood agar and Mac Conkey's agar. Plates were examined for the growth of bacteria. All positive cultures were identified by their characteristic appearance on their respective media, Gram staining reaction and were confirmed by the pattern of biochemical reactions using the standard methods (Mackie and MacCartney).

\section{Antibiotic susceptibility testing}

The antibiotic susceptibility test was done by Kirby-Bauer disk diffusion method. Zone sizes were measured and interpreted according to CLSI standards. Drug resistant strains in primary screening were further processed for the detection of extended spectrum beta lactamases (ESBL) in gram negative bacterial isolates and methicillin resistance in Staphylococcus aureus strains.

The isolates were considered as Methicillin Resistant Staphylococcus aureus (MRSA) if the zone of inhibition was less than $21 \mathrm{~mm}$ and Methicillin Sensitive Staphylococcus aureus (MSSA) if it was $\geq 22 \mathrm{~mm}$. For Coagulase negative Staphylococcus (CONS), if the zone of inhibition was less than $24 \mathrm{~mm}$ considered as Methicillin resistant Coagulase-negative Staphylococcus (MRCONS) and if it was $\geq 25 \mathrm{~mm}$ Methicillin sensitive Coagulase negative Staphylococcus (MSCONS) (CLSI, 2014). 
ESBL producers were detected by combination disk method using cefotaxime $(30 \mu \mathrm{g})$ and cefotaxime/clavulanate (30/10 $\mu \mathrm{g})$ (Himedia Mumbai, India). An increase of $5 \mathrm{~mm}$ in the zone of inhibition in a disk containing clavulanate compared to the drug alone was considered as positive for ESBL producers.

\section{Statistical analysis}

Data was entered into a computerized Excel (Microsoft Excel 2009) spread sheet, and subsequently it was analyzed using SPSS software. Descriptive statistics (means and percentages) were used wherever necessary.

\section{Results and Discussion}

A total of 3255 blood samples from paediatric cases with suspected history of sepsis were received to the department of microbiology during the period from January 2014 to September 2015. Out of which $4.4 \%$ (144/3255) were culture positive (paired sample), while $95.6 \% \quad(3111 / 3255)$ were sterile. Table 1 shows age wise distribution of samples, of which children between 1month and 1 year $(66 \%)$ constituted majority. The most common isolate in this study was gram positive organisms which accounts for $56.94 \%$ (82/144) and gram negative organisms were $43.05 \%$ (62/144). Among gram positive organisms, the predominant isolate was Coagulase negative Staphylococci (53.65\%) followed by Staphylococcus aureus (25.60\%). Among gram negative bacilli, the predominant isolate was $K$. pneumoniae (35.48\%) followed by Escherichia coli (24.19\%), Pseudomonas aeruginosa (16.12\%) and Non fermenting gram negative bacilli $(9.67 \%)$ (Table 2).

The antibiotic susceptibility pattern of gram positive organisms and gram negative organisms were detailed in the tables 3 and 4 respectively.
Septicaemia is a clinical syndrome associated with considerable morbidity and mortality. The timely detection of bacteraemia can have a profound influence on the final clinical outcome. Culture positivity in our study was $4.4 \%$, which is close to study done by Thacker et al., $(6.97 \%)$. The difference in positivity could be due collection of single sample in patients at our institution. Male preponderance was found in our study which is similar to that of Tallur et al., (2000).

In the present study gram positive and gram negative organisms accounted for $56.94 \%$ and $43.05 \%$ respectively, which is in concordant with that of Mikulska et al., (2014) (55\% and 45\%). Among gram positive and gram negative organisms, Coagulase negative Staphylococcus (53.65\%) and Klebsiella pneumoniae $(35.48 \%)$ respectively were the most common isolates, similarly was observed in Premalatha et al., (2014) (21.21\% and $36.36 \%$ ) study.

Our study showed Coagulase negative Staphylococci was the most common blood culture isolate, which are often skin colonizers and appear in blood culture as common contaminants during the time of sample collection. Skin disinfection with $70 \%$ isopropyl alcohol at the time of venepuncture can limit this potential contaminant species to a large extent.

In this study, the proportion of MRSA was $27.27 \%$. The occurrence of MRSA is more common because of indiscriminate use of higher antibiotics as an emergency empirical therapy. Vancomycin remains the drug of choice for the Gram positive bacterial isolates. Klebsiella pneumoniae was more sensitive to imipenem, meropenem, ertapenem, gentamicin and amikacin, and resistant to ampicillin, amoxy-clav, cephalosporins and ciprofloxacin, which is similar to study by Premalatha et al., (2014). 
Table.1 Age and gender wise distribution of isolates

\begin{tabular}{|c|c|c|c|}
\hline Age & Male (\%) & Female (\%) & Total \\
\hline 0-1 Month & 26 & 15 & 41 \\
\hline 1 Month- 1 Year & 36 & 30 & 66 \\
\hline 1 Year- 18 Years & 18 & 19 & 37 \\
\hline & $\mathbf{8 0}(\mathbf{5 5 . 5})$ & $\mathbf{6 4}(\mathbf{4 4 . 5 \% )}$ & $\mathbf{1 4 4}$ \\
\hline
\end{tabular}

Table.2 Distribution of isolates

\begin{tabular}{|l|c|c|}
\hline Name of the isolate & Total no. & Percentage \\
\hline Gram positive organisms & $\mathbf{8 2}$ & $\mathbf{5 6 . 9 4}$ \\
\hline $\begin{array}{l}\text { Coagulase negative } \\
\text { Staphylococcus }\end{array}$ & 44 & 53.65 \\
\hline Staphylococcus aureus & 21 & 25.60 \\
\hline Streptococcus species & 11 & 13.41 \\
\hline Enterococcus species & 06 & 7.31 \\
\hline Gram negative organisms & $\mathbf{6 2}$ & $\mathbf{4 3 . 0 5 \%}$ \\
\hline Klebsiella pneumoniae & 22 & 35.48 \\
\hline Escherichia coli & 15 & 24.19 \\
\hline Pseudomonas aeruginosa & 10 & 16.12 \\
\hline Non-fermenting gram negative rods & 06 & 9.67 \\
\hline Salmonella typhi & 02 & 3.22 \\
\hline Klebsiella oxytoca & 01 & 1.61 \\
\hline Citrobacter koseri & 01 & 1.61 \\
\hline Citrobacter freundii & 01 & 1.61 \\
\hline Enterobacter species & 01 & 1.61 \\
\hline Aeromonas species & 01 & 1.61 \\
\hline Proteus mirabilis & 01 & 1.61 \\
\hline Providencia species & 01 & 1.61 \\
\hline Total no. of isolates & $\mathbf{1 4 4}$ & \\
\hline
\end{tabular}

Table.3 Antibiotic susceptibility pattern of gram positive organisms

\begin{tabular}{|c|c|c|c|c|c|c|c|c|c|c|c|c|c|c|c|}
\hline Organism & $\mathbf{P}$ & $\mathbf{A m p}$ & $\begin{array}{c}\mathbf{A m} \\
\mathbf{c}\end{array}$ & $\mathbf{O x}$ & $\mathbf{C n}$ & $\mathbf{C x}$ & $\mathbf{C i p}$ & $\mathbf{G}$ & $\mathbf{S x t}$ & $\mathbf{D o}$ & $\mathbf{E}$ & $\mathbf{C D}$ & $\mathbf{L z}$ & $\mathbf{V a}$ & $\mathbf{T e}$ \\
\hline MRSA (6) & 0 & 0 & 0 & 0 & 0 & 0 & 33.33 & 100 & 66.66 & 83.33 & 83.33 & 100 & 100 & 100 & 100 \\
\hline MSSA (15) & 33.33 & 80 & 100 & 100 & 100 & 100 & 66.66 & 100 & 86.66 & 86.66 & 86.66 & 100 & 100 & 100 & 100 \\
\hline $\begin{array}{c}\text { MSCONS } \\
(\mathbf{4 4 )}\end{array}$ & 25 & 25 & 100 & 100 & 100 & 100 & 75 & 79.54 & 75 & 90.90 & 75 & 79.54 & 100 & 100 & 100 \\
\hline $\begin{array}{c}\text { Streptococcus } \\
\text { spp (11) }\end{array}$ & 100 & 100 & 100 & 100 & 100 & 100 & 81.81 & - & - & - & 100 & 100 & 100 & 100 & 100 \\
\hline $\begin{array}{c}\text { Enterococcus } \\
\text { spp (6) }\end{array}$ & 50 & 83.33 & 100 & - & 0 & 0 & 50 & 50 & - & - & - & - & 100 & 100 & 100 \\
\hline
\end{tabular}

P- Penicillin, Amp- Ampicillin, Amc- Amoxy-clavunate, Ox- oxacillin, Cn- cephalexin,

Cx-Cefoxitin, Cip- Ciprofloxacin, G- Gentamicin, Sxt- Cotrimoxazole, Do- Doxycycline,

E- Erythromycin, CD- Clindamycin, Lz- Linezolid, Va- Vancomycin, Te- Teicoplanin. 
Table.4 Antibiotic susceptibility pattern of gram negative organisms

\begin{tabular}{|c|c|c|c|c|c|c|c|c|c|c|c|c|c|c|c|c|c|c|c|c|}
\hline Organism & & & & & & & & & & & & & & & & & & & & \\
\hline & $\overline{\mathrm{z}}$ & $\ddot{\Xi}$ & $\ddot{E}$ & Eี & E & లี & Ũ & û & $\sum$ & $\equiv$ & 馬 & 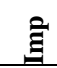 & in & ט & 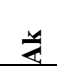 & $\hat{\Xi}$ & ¿ิ & $\vec{\jmath}$ & $\stackrel{\infty}{=}$ & $\bar{v}$ \\
\hline $\begin{array}{l}\text { K. } \\
\text { pneumoniae } \\
\text { (22) }\end{array}$ & 0 & 20 & - & 22 & 22 & 25 & 40 & 60 & 33 & 57 & 77 & 80 & 77 & 87 & 80 & 100 & 40 & 44 & 100 & 100 \\
\hline E. coli $(15)$ & 16 & 20 & - & - & 16 & 20 & 16 & 40 & 50 & 80 & 66 & 100 & 83 & 50 & 83 & 100 & 16 & 16 & 100 & 100 \\
\hline $\begin{array}{l}\text { P. aeruginosa } \\
\text { (10) }\end{array}$ & - & - & 100 & - & - & 75 & - & - & 100 & - & - & 100 & 50 & 100 & 66 & 100 & 75 & - & 100 & 100 \\
\hline NFGNB (6) & - & - & 0 & - & - & 80 & - & - & - & 70 & - & - & 80 & - & - & 85 & - & - & 100 & 100 \\
\hline S. typhi (2) & 100 & - & - & - & - & - & 100 & - & 100 & 100 & 100 & 100 & 100 & 50 & 50 & - & 50 & 100 & 100 & 100 \\
\hline K. oxytoca $(1)$ & 0 & 30 & - & 20 & 28 & 28 & 40 & 70 & 35 & 60 & 80 & 88 & 76 & 92 & 80 & 100 & 40 & 42 & 100 & 100 \\
\hline $\begin{array}{l}\text { Citrobacter } \\
\text { freundii (1) }\end{array}$ & 0 & 0 & 0 & 0 & 0 & 100 & 100 & 100 & 100 & 100 & 100 & 100 & 100 & 100 & 100 & 100 & 100 & 100 & 100 & 100 \\
\hline $\begin{array}{l}\text { Citrobacter } \\
\text { koseri (1) }\end{array}$ & 0 & 0 & 0 & 0 & 0 & 100 & 100 & 100 & 100 & 100 & 100 & 100 & 100 & 100 & 100 & 100 & 100 & 100 & 100 & 100 \\
\hline $\begin{array}{l}\text { Enterobacter } \\
\text { spp. (1) }\end{array}$ & 0 & 0 & 0 & 0 & 0 & 100 & 100 & 0 & 100 & 100 & 100 & 100 & 100 & 100 & 100 & - & 100 & 100 & 100 & 100 \\
\hline $\begin{array}{l}\text { Aeromonas } \\
\text { spp. (1) }\end{array}$ & 0 & - & 0 & - & - & - & - & - & 100 & 100 & 100 & 100 & 100 & 100 & 100 & - & 100 & 100 & 100 & 100 \\
\hline $\begin{array}{l}\text { Proteus } \\
\text { mirabilis (1) }\end{array}$ & 100 & $\begin{array}{l}10 \\
0\end{array}$ & 100 & $\begin{array}{l}10 \\
0\end{array}$ & 100 & 100 & 100 & 100 & 100 & 100 & 100 & 100 & 100 & 100 & 100 & 100 & 100 & 100 & 100 & 100 \\
\hline $\begin{array}{l}\text { Providencia } \\
\text { spp. (1) }\end{array}$ & 0 & 0 & 0 & 0 & 0 & 0 & 0 & 0 & 100 & 100 & 100 & 100 & 100 & 100 & 100 & 100 & 100 & 0 & 100 & 100 \\
\hline
\end{tabular}

Amp- Ampicillin, Amc- Amoxy-clavunate, Pi- Piperacillin,Cn - Cephalexin, Cxm- Cefuroxime, Caz- Ceftazidime, Ctx- Cefotaxime, Cx- Cefoxitin, At-Aztreonam, Ptz- Piperacillin- tazobactam, Ert- Ertapenem, Imp- Imipenem, Mrp- Meropenem, G- Gentamicin, Ak- Amikacin, Tob- Tobramycin, Cip- Ciprofloxacin, Sxt- Cotrimoxazole, TgTigecycline, Cl- Colistin

Rate of ESBL producers in our study is $12.9 \%$ which agrees with study done by Prabhash et al., (2010) $15.15 \%$. All gram negative isolates were $100 \%$ sensitive to colistin and tigecycline, so was observed in Premalatha et al., (2014) study.

In conclusion, it is evident from this study that among gram positive organisms CONS, and $S$. aureus and among gram-negative organisms Klebsiella pneumoniae, E. coli are the leading cause of paediatric sepsis. Also the most challenging observation was the resistance pattern of these isolates to multiple antibiotics. The main forces driving the increase in antimicrobial resistant bacteria are the inappropriate use of antibiotics. Specific antibiotic utilization strategies like antibiotic restriction, combination therapy and antibiotic escalation and de-escalation may help to decrease or prevent the emergence of resistance.

\section{Recommendation}

Continuous monitoring of paediatric septicaemia and formulation of appropriate antibiotic policy is the need of the hour for surveillance and control of infection in the hospital.

\section{References}

Anuradha, D., Saraswathi, N.K., Gogate, A., Fernandes, A.R. 1995. Bacteremia in hospitalized children - A one year prospective study, Indian J. Med. 
Microbiol., 13: 72-5.

Elster, T., Beata Czeszynska, M., Sochaczewska, D., Konefal, H., BarylaPankiewicz, E. 2009. Analysis of risk factors for nosocomial infectons in the Neonatal Intensive Care Unit of the Pomeranian Medical University in Szczecin in the years 2005-2008. Ginekol Pol., 80(8): 609-14.

Enrione, M.A., Powell, K.R. 2007. Sepsis, septic shock and systemic inflammatory response syndrome. In: Kleigman RM, Behraman RE, Jenson HB, Stanton BF, editors. Nelson textbook of paediatrics. Philadelphia: WB Saunders; p. 1094.

Forbes, B.A., Sahm, D.F., Weissfeld, A.S. Missouri: Mosby Elsevier; 2007. Bailey and Scott's Diagnostic Microbiology, p. 779 .

Gomaa, H.H.A., Udo, E.E., Rajaram, U. 2001. Neonatal septicemia in Al-Jahra hospital, Kuwait: Etiologic agents and antibiotic sensitivity patterns. Med. Princ. Pract., 10: $145-50$.

Meremkwer, M.M., Nwachukwu, C.E., Asuquo, A.E., Okebe, J., Utsalo, S.J. 2005. Bacterial isolates from blood cultures of children with suspected septicaemia in Calabar, Nigeria. BMC Infect. Dis., 5: $110-5$.

Mikulska, M., Viscoli, C., Orasch, C., Livermore, D.M., Averbuch, D., Cordonnier, C., et al. 2014. Aetiology and resistance in bacteraemias among adult and paediatrichaematology and cancer patients. J. Infect., 68: 321-31.

Nwadioha, S.I., Nwokedi, E.O.P., Kashibu, E., Odimayo, M.S., Okwori, E.E. 2010. A review of bacterial isolates in blood cultures of children with septicaemia in a Nigerian tertiary Hospital. Afr. J. Microbiol. Res., 4: 222-5.

Prabhash, K., Medhekar, A., Ghadyalpatil, N., Noronha, V., Biswas, S., Kurkure, P., et al., 2010. Blood stream infections in cancer patients: A single center experience of isolates and sensitivity pattern. Indian J. Cancer, 47: 184-8.

Premalatha, D.E., Mallikarjun, K., Halesh, L.H., Siddesh, K.C., Prakash, N. 2014. The Bacterial Profile and Antibiogram of Neonatal Septicaemia in a Tertiary Care Hospital, Int. J. Recent Trends in Sci. Technol., ISSN 2277-2812 E-ISSN 22498109, 10(3): 451-455.

Shrestha, P., Das, B.K., Bhatta, N.K., Jha, D.K., Das, B., Setia, A., et al. 2008. Clinical and bacteriological profiles of blood culture positive sepsis in newborns. $J$. Nepal Paediatr., 7: 64-7.

Tallur, A.V., Kasturi, Shobha D. Nadgir and B.V.S. $2000 . \quad$ Krishna.Clinicobacteriological study of neonatal septicemia in Hubli. Ind. J. Pediatric., 3: 169-174.

Thacker, N., Pereira, N., Banavali, S.D., Narula, G., Vora, T., Chinnaswamy, G. et al. 2014. Epidemiology of blood stream infections in pediatric patients at a tertiary care cancer centre. Ind. J. Cancer, 51(4).

Wisplinghoff, H., Seifert, H., Richard, Wenzel, P., Edmond, M.B. 2003. Current Trends in the Epidemiology of Nosocomial Bloodstream Infections in Patients with Hematological Malignancies and Solid Neoplasms in Hospitals in the United States.BSI in Patients with Malignancies, CID, 36: 1103-1110.

\section{How to cite this article:}

Ramya, A., S. Sangeetha, S.A. Lakshminarayana and Prakash, R. 2017. Blood Stream Infection in Pediatric Patients of a Tertiary Care Hospital: A Bacteriological and Antimicrobial Profile. Int.J.Curr.Microbiol.App.Sci. 6(3): 1444-1449. doi: https://doi.org/10.20546/ijcmas.2017.603.164 